\title{
Paget's disease of the male breast: a case report
}

\author{
Masayuki Akita ${ }^{1 *}$, Nobuya Kusunoki ${ }^{2}$, Takahiro Nakajima', Shiro Takase ${ }^{1}$ Yoko Maekawa ${ }^{3}$, Kazuyoshi Kajimoto ${ }^{4}$ \\ and Masakazu Ohno ${ }^{1}$
}

\begin{abstract}
The patient was a 91-year-old man with change in nipple appearance, itching and redness, and a palpable breast mass. At presentation, mammary Paget's disease (PD) was clinically suspected. Skin biopsy was performed and showed epidermis invaded by Paget cells, characterized by hyperchromatic nuclei and abundant pale-staining cytoplasm. Computed tomography and mammary ultrasonography confirmed the absence of an underlying invasive carcinoma, and the patient underwent right mastectomy and sentinel lymph node biopsy (SLNB). Both sentinel lymph nodes were found to be negative perioperatively, and further axillary dissection was not performed. Pathological results revealed no malignancy under the nipple, yet the Paget cells were more widely spread than expected. The patient was followed up without the need of postoperative chemotherapy. Male mammary PD is an extremely rare breast cancer, and there is no standard preoperative assessment or operative procedure. Mammography is many times unable to detect possible underlying breast carcinoma in female patients with mammary PD, and previous studies have reported that the detection rate was less than $50 \%$. However, some researchers reported that magnetic resonance imaging (MRI) might be more detectable to confirm the extent of the cancer. The extent of the skin change around the nipple is often different from the actual perimeter of Paget cells. In extra-mammary PD, mapping biopsy is known to be useful to determine areas free of cancer. The benefits of SLNB have also been demonstrated for the management of less invasive breast cancers, and previous reports have shown that the use of SLNB is reasonable for treatment of mammary PD without underlying invasive cancer. MRI, mapping biopsy, and SLNB are all less invasive procedures and thus may be suitable for treatment of male mammary PD.
\end{abstract}

Keywords: Male breast cancer; Mammary Paget's disease; Sentinel lymph node biopsy; Mapping biopsy

\section{Background}

Mammary Paget's disease (PD) is rare and comprises about $1 \%$ of all breast cancers. Male breast cancer is also uncommon, representing approximately $1.0 \%$ of all breast malignancies. Thus, male mammary PD of the breast is an extremely rare occurrence $[1,2]$. Between 1980 and 2015, eight case reports were identified from the MEDLINE by keywords, "mammary Paget disease, man" (Table 1). Most patients with mammary PD initially note the presence of redness, erosion, or pruritus of the nipple and are diagnosed by skin biopsy or nipple discharge cytology, which is characterized by malignant glandular cells with clear cytoplasm and

\footnotetext{
* Correspondence: bokuakkey70033@gmail.com

'Department of Surgery, Hyogo Prefectural Kaibara Hospital, 5208-1 Kaibara, Kaibara-cho, Tamba, Japan

Full list of author information is available at the end of the article
}

eccentric, hyperchromatic nuclei within the epidermis. PD of the breast is accompanied by invasive or noninvasive underlying carcinomas in 84 94\% of the cases [3-5], and the prognosis of mammary PD is correlated with the stage of the underlying carcinoma. From the preoperative assessment of the extent of the spread of the tumor, surgeons decide the operative management of the mammary PD, mastectomy with or without an axial lymph node dissection. This report presents a preoperative and surgical strategy for male mammary PD.

\section{Case presentation}

The patient was a 91-year-old man with no family history of testicle, breast, and ovarian disease, who noted itchiness and redness around his right nipple with a palpable mass underneath (Fig. 1). Physical examination revealed a $1.0-\mathrm{cm}$ movable mass underneath the nipple with no axial

\section{实 Springer}


Table 1 Mammary Paget's disease of the man in the literature

\begin{tabular}{|c|c|c|c|c|c|c|c|}
\hline Patient no. & Author & Age & Symptoms & Palpable mass & Treatment & Axillary metastasis & Follow-up \\
\hline 1 & Lancer HA [9] & 81 & $\begin{array}{l}\text { Irritation, } \\
\text { redness }\end{array}$ & - & Mastectomy & - & $\begin{array}{l}\text { Disease free } 5 \\
\text { months }\end{array}$ \\
\hline 2 & Serour F [6] & 73 & $\begin{array}{l}\text { Lump, } \\
\text { eczema }\end{array}$ & + & $\begin{array}{l}\text { Mastectomy } \\
\text { irradiation }\end{array}$ & + & $\begin{array}{l}\text { Disease free } 8 \\
\text { years }\end{array}$ \\
\hline 3 & O'Sullivan ST [1] & 72 & $\begin{array}{l}\text { Erythema, } \\
\text { eczema }\end{array}$ & + & Simple mastectomy & $\mathrm{N} / \mathrm{A}$ & alive 9 months \\
\hline 4 & Hayes R [7] & 65 & $\begin{array}{l}\text { Bloody discharge, } \\
\text { ulceration }\end{array}$ & - & $\begin{array}{l}\text { Mastectomy adjuvant } \\
\text { chemotherapy }\end{array}$ & + & $\begin{array}{l}\text { Disease free } 5 \\
\text { months }\end{array}$ \\
\hline 5 & Nakamura S [8] & 83 & $\begin{array}{l}\text { Bloody discharge, } \\
\text { pigmented }\end{array}$ & - & Simple mastectomy & N/A & $\begin{array}{l}\text { Disease free } 9 \\
\text { months }\end{array}$ \\
\hline 6 & Bernardi M [19] & 52 & $\begin{array}{l}\text { Discolored, } \\
\text { pruritus }\end{array}$ & - & $\begin{array}{l}\text { Failed to return } \\
\text { for follow-up }\end{array}$ & N/A & N/A \\
\hline 7 & Ucar AE [10] & 74 & Bilateral excoriation & $\mathrm{rt}+\mathrm{It}-$ & $\begin{array}{l}\text { Mastectomy adjuvant } \\
\text { chemo-radiotherapy }\end{array}$ & - & N/A \\
\hline 8 & Harroudi T [2] & 61 & Pruritus, erythema & + & $\begin{array}{l}\text { Mastectomy adjuvant } \\
\text { chemo-radiotherapy }\end{array}$ & - & $\begin{array}{l}\text { Disease free } 2 \\
\text { years }\end{array}$ \\
\hline 9 & Current case & 91 & Itching, redness & - & Mastectomy SLNB & - & $\begin{array}{l}\text { Disease free } 1 \\
\text { years }\end{array}$ \\
\hline
\end{tabular}

lymphadenopathy. The full-thickness skin biopsy identified Paget cells in the epidermis, and immunohistochemistry showed these cells were stained strongly for cytokeratin 7 , cytokeratin 20, and with alcian blue and was negative for gross cystic disease fluid protein 15; these results were consistent with PD. The evaluation of the overexpression of human EGFR-related 2 protein showed weakly positive cells (score2: equivocal). The mass under his nipple was diagnosed as gynecomastia by mammary ultrasonography (Fig. 2). Blood examination showed normal tumor markers (squamous cell carcinoma, $1.1 \mathrm{ng} / \mathrm{dl}$, carcinoembryonic antigen, $5.2 \mathrm{ng} / \mathrm{dl}$, carbohydrate antigen 15-3, $9.6 \mathrm{ng} / \mathrm{dl}$ ) and normal liver function. Computed tomography confirmed absence of an invasive tumor and distant

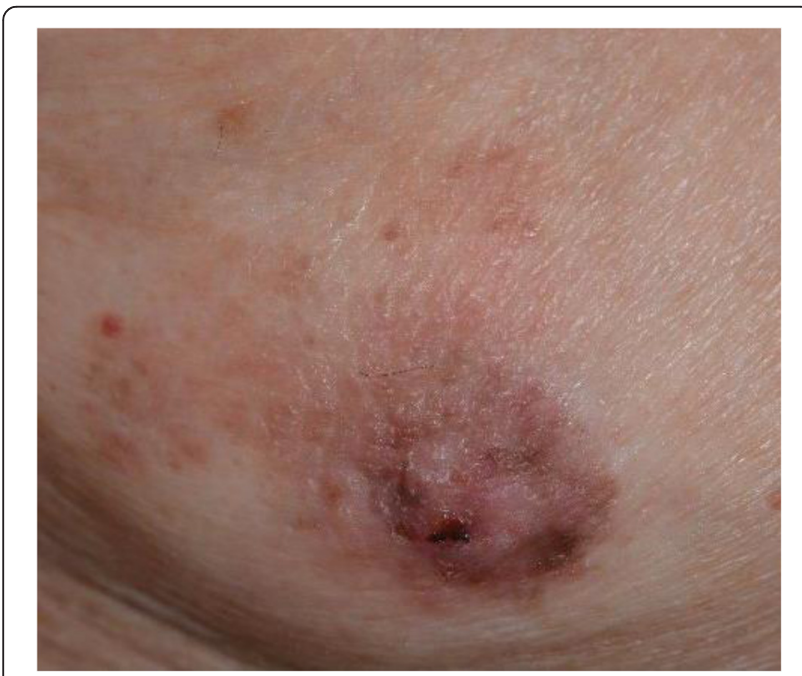

Fig. 1 Right breast at initial presentation. Erosion and redness of the nipple were noted, and lateral accretion of Paget's disease was suspected. A 1.0-cm movable lump was identified in the breast metastases. The patient underwent right total mastectomy and right sentinel lymph node biopsy. Two sentinel lymph nodes were removed, and due to no metastases in the axilla, axillary lymph node dissection was not performed. No underlying carcinoma was found in the resected specimen, and Paget cells were found to be spread more extensively to the skin than expected (Fig 3), although the resected margin was negative (Fig. 4). Due to the patient's age and no invasive nest other than Paget infiltration to the skin, the patient was followed up without the need of postoperative adjuvant therapy.

\section{Conclusions}

Between 1980 and 2015, eight case reports were identified from the MEDLINE (Table 1). The age of patients

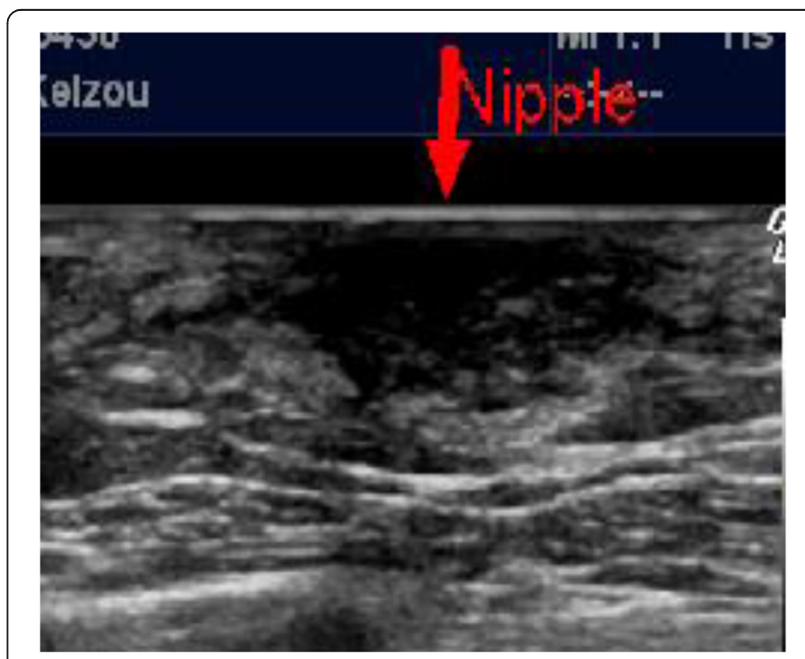

Fig. 2 Mammary ultrasonography. A poorly marginated and low echoic area was detected under the nipple. The palpable mass was diagnosed as gynecomastia 


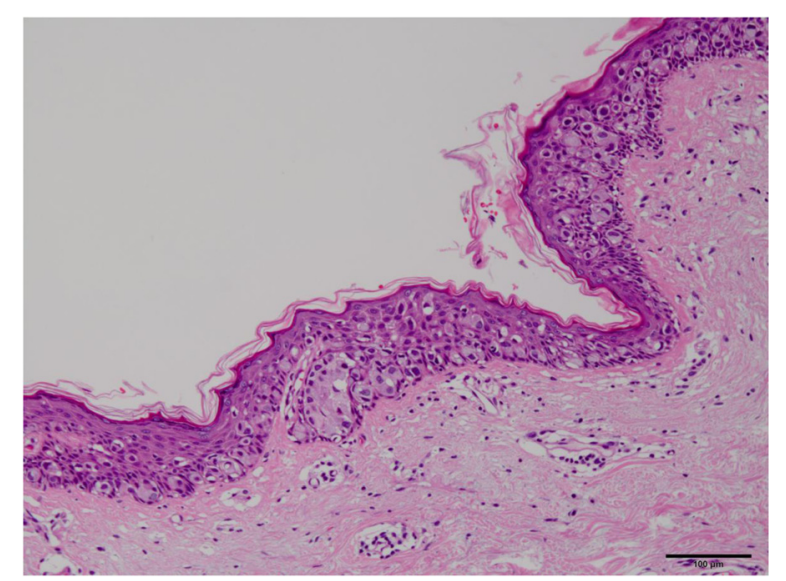

Fig. 3 Histopathological findings of the resected specimen (Hematoxylin-eosin stain, $\times 100$ ). Paget's cells, which were characterized by clear cytoplasm and hyperchromatic nuclei, were detected within the epidermis. Deep infiltration was not observed

varies from 52 to 91 years. Almost all patients presented to the outpatient department with a chief complaint of skin changes around the nipple. Some also noticed the nipple bloody discharge, and only one did an underlying palpable mass as a primary symptom [6-8]. In physical examinations, none of them had axillary lymphadenopathy, but at least two patients had axillary metastases in the resected specimen $[6,7]$. The rate of patients without underlying carcinomas may be higher than females. However, much a short follow-up period, none of the patients have died of the recurrence of the mammary PD. Because survival depends on the stage of the underlying carcinoma, the low rate of the underlying tumor seems to result in good prognosis $[2,6,9,10]$. The effectiveness of axillary lymph nodes dissection, irradiation, or adjuvant chemotherapy for male mammary PD

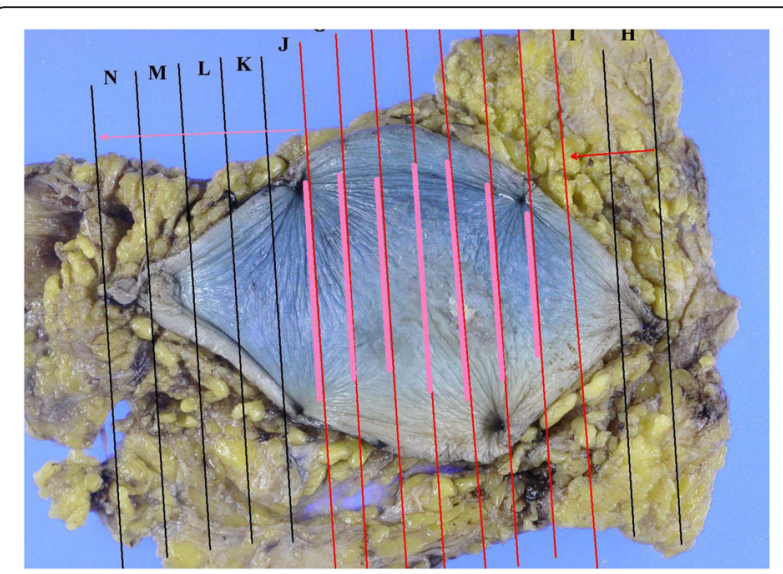

Fig. 4 Excised specimen from the mastectomy. A histopathological cancer map of the mastectomy specimen with the bold pink lines showing the detected malignant area. This area was not consistent with the preoperative assessment. Negative margins were confirmed is still uncertain, but as with female mammary PD, these options should be considered on the basis of the stage of cancer progression.

In clinically suspected cases of mammary PD, fullthickness skin biopsy is used to pathologically obtain a diagnosis as mammary $\mathrm{PD}$, and mammography and mammary ultrasonography are used to identify the presence of an underlying carcinoma. Female mammary PD patients (84 94\%) had an underlying invasive or noninvasive carcinoma [3-5]. However, mammography is able to detect only $47 \sim 59 \%$ of the underlying neoplasms confirmed by histology [3, 11, 12]; one-third of PD patients had an invasive cancer without a palpable mass or mammographic finding [5]. On the other hand, magnetic resonance imaging (MRI) is able to reveal the presence of $78 \sim 98 \%$ of underlying cancers, and Amano et al. has suggested that MRI is very useful to assess the extent of these cancers accurately $[3,13]$.

Some investigators have reported that local recurrence is possible in patients with PD. One possible cause of recurrence may be insufficient preoperative evaluation of the lateral and vertical extent of the disease. In the present case, the extent of malignancy in the resected specimen was inconsistent with the gross changes of skin condition. Intraoperative consultation may be helpful for confirmation of the negative resection stump. For example, in patients with extra-mammary PD, mapping biopsy is often used preoperatively to evaluate dermal infiltration, and a $1-\mathrm{cm}$ margin resection is acceptable [14-16].

Sentinel lymph node biopsy (SLNB) has been used as a standard option in clinically node-negative mammary cancer although the effectiveness of the use of SLNB for treatment of mammary PD has not been established. Laronga et al. published a database review comparing 36 patients with mammary PD who underwent SLNB and 18 patients who did not undergo SLN; 7 patients had sentinel lymph node metastases, all of which were associated with an underlying carcinoma. However, overall and disease-free survival did not differ significantly between the groups [17]. Two other reports have shown that not only patients with underlying invasive carcinoma had sentinel lymph node metastases but also patients without clinical evidence of an underlying carcinoma [18]. Therefore, because the reduced invasiveness of SLNB, this procedure was worth considering in the present case regardless of findings suggestive of an underlying carcinoma.

Although almost all the studies above have been with female mammary PD patients, given the reduced invasiveness of MRI, mapping biopsy, and SLNB, we suggest the use of these procedures for male patients with mammary PD to accurately assess the extent of the tumor. 


\section{Consent}

Written informed consent was obtained from the patient for publication of this case report and any accompanying images. A copy of the written consent is available for review by the Editor-in-Chief of this journal.

\section{Abbreviations}

PD: Paget's disease; MRI: magnetic resonance image; SLNB: sentinel lymph node biopsy.

\section{Competing interests}

The authors declare that they have no competing interests.

\section{Authors' contributions}

$\mathrm{AM}$ and $\mathrm{KN}$ participated in the design of the study and helped to draft the manuscript. NT, TS, MY, and OM conceived of the study and participated in its design and coordination. KK has been involved in the diagnostic pathology studies. All authors read and approved the final manuscript.

\section{Acknowledgements}

We thank Dr. Kumano for teaching dermatological findings.

\section{Author details}

'Department of Surgery, Hyogo Prefectural Kaibara Hospital, 5208-1 Kaibara Kaibara-cho, Tamba, Japan. ${ }^{2}$ Division of Hepato-Biliary-Pancreatic Surgery, Department of Surgery, Kobe University Graduate School of Medicine, 7-5-2 Kusunoki-cho, Chuo-ku, Kobe, Japan. ${ }^{3}$ Department of Surgery, National Hospital Organization Kobe Medical Center, 3-1-1 Nishiochiai, Suma-ku, Kobe, Japan. ${ }^{4}$ Department of Pathology, Hyogo Cancer Center, 13-70, Kitaoji-cho, Akashi, Japan.

Received: 20 January 2015 Accepted: 5 October 2015

Published online: 15 October 2015

\section{References}

1. O'Sullivan ST, McGreal GT, Lyons A, Burke L, Geoghegan JG, Brady MP. Paget's disease of the breast in a man without underlying breast carcinoma. J Clin Pathol. 1994;47:851-2.

2. El Harroudi T, Tijami F, El Otmany A, Jalil A. Paget disease of the male nipple. J Cancer Res Ther. 2010;6:95-6.

3. Trebska-McGowan K, Terracina KP, Takabe K. Updete on the surgical management of Paget's disease. Gland Surgery. 2013;2:137-42.

4. Morrogh M, Morris EA, Liberman L, Van Zee K, Cody 3rd HS, King TA. MRI identifies otherwise occult disease in select patients with Paget disease of the nipple. J Am Coll Surg. 2008:206:316-21.

5. Sukumvanich P, Bentrem DJ, Cody 3rd HS, Brogi E, Fey JV, Borgen PI. The role of sentinel lymph node biopsy in Paget's disease of the breast. Ann Surg Oncol. 2007;14:1020-3.

6. Serour F, Birkenfeld S, Amsterdam E, Treshchan O, Krispin M. Paget's Disease of the male breast. Cancer. 1988:62:601-5.

7. Hayes R, Cummings B, Miller RA, Guha AK. Male Paget's disease of the breast. J Cutan Med Surg. 2000;4:208-12.

8. Nakamura S, Ishida-Yamamoto A, Takahashi H, Hashimoto Y, Yokoo H, lizuka $\mathrm{H}$. Pigmented Paget's disease of the male breast: report of a case. Dermatology. 2001;202:134-7.

9. Lancer HA, Moschella SL. Paget's disease of the male breast. J Am Acad Dermatol. 1982;7:393-6.

10. Ucar AE, Korukluoglu B, Ergul E, Aydin R, Kusdemir A. Bilateral paget disease of the male nipple: first report. Breast. 2008;17:317-8.

11. Zakaria S, Pantvaidya G, Ghosh K, Degnim AC. Paget's disease of the breast: accuracy of preoperative assessment. Breast Cancer Res Treat. 2007;102:137-42.

12. Günhan-Bilgen I, Oktay A. Paget's disease of the breast: clinical, mammographic, sonographic and pathologic findings in 52 cases. Eur J Radiol. 2006;60:156-63.

13. Amano G, Yajima M, Moroboshi Y, Kuriya Y, Ohuchi N. MRI accurately depicts underlying DCIS in a patient with Paget's disease of the breast without palpable mass and mammography findings. Jpn J Clin Oncol. 2005;35:149-53.
14. Murata Y, Kumano K. Extramammary Paget's disease of the genitalia with clinically clear margins can be adequately resected with $1 \mathrm{~cm}$ margin. Eur J Dermatol. 2005;15:168-70.

15. Gunn RA MD, Gallanger HS MD. Vulvar Paget's disease: a topographic study. Cancer. 1980;46:590-4.

16. Kim BJ, Park SK, Chang H. The effectiveness of mapping biopsy in patients with extramammary Paget's disease. Arch plast surg. 2014;41:753-8.

17. Laronga C, Hasson D, Hoover S, Cox J, Cantor A, Cox C, et al. Paget's disease in the era of sentinel lymph node biopsy. Am J Surg. 2006;192:481-3.

18. Caliskan M, Gatti G, Sosnovskikh I, Rotmensz N, Botteri E, Musmeci S, et al. Paget's disease of the breast: the experience of the European Institute of Oncology and review of the literature. Breast Cancer Res Treat. 2008;14:1020-3.

19. Bernardi M, Brown AS, Malone JC, Callen JP. Paget disease in a man. Arch Dermatol. 2008;144:1660-1.

\section{Submit your manuscript to a SpringerOpen ${ }^{\circ}$ journal and benefit from:}

- Convenient online submission

- Rigorous peer review

- Immediate publication on acceptance

- Open access: articles freely available online

- High visibility within the field

- Retaining the copyright to your article

Submit your next manuscript at $>$ springeropen.com 